ISSN 1991- 8690

website : http:// jsci.utq.edu.iq

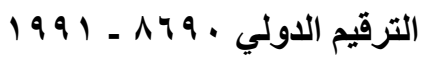

Email: utjsci@utq.edu.iq

\title{
Dielectrical and Electrical Properties of Polystyrene films Doped with Copper Sulfate
}

\author{
Hussein Neama Najeeb \\ Ahmed Kadem Kodeary \\ Rafia Tiema Ahmed \\ Babylon University -Collage of Science for Women
}

\begin{abstract}
$\underline{\text { Abstract }}$
The electrical characteristics of polystyrene doped with different concentrations $(0,1,2,3$, and $4 \mathrm{wt} \%)$ of Copper Sulfate $\mathrm{CuSO}_{4} .5 \mathrm{H}_{2} \mathrm{O}$ powder were studied. The films are prepared using solution casting technique, in order to investigate the effect of Copper Sulfate $\mathrm{CuSO}_{4} \cdot 5 \mathrm{H}_{2} \mathrm{O}$ additions on the electrical properties of PS host. The D.C conductivity measured by measuring the D.C electrical resistance using the( Keithly Electrometer type 616C), and for different temperatures ranging from $(30-80)^{\circ} \mathrm{C}$. The dielectric properties measured by measuring the capacitor and the loss angle tangent as a function to the alternating electric field frequency using the (Agilent impedance analyzer 4294A), within the frequency range $\left(50-6 \times 10^{6}\right) \mathrm{Hz}$ at room temperature. The experimental results showed that the dielectric constant is decrease with increase frequency of applied electrical field and increase with increasing concentrations, dielectric loss is decrease with increasing frequency of applied electrical field to be $0.5 \mathrm{MHz}$ after this it was increasing , A.C electrical conductivity are increasing with increasing frequency of applied electrical field , also, the results showed that the D.C electrical conductivity are increasing with increase concentration of PS and temperature, activation energy are decreasing with increase concentration of additive salt
\end{abstract}
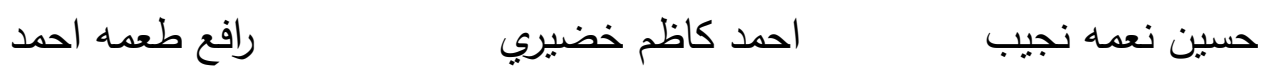

$\underline{\underline{ا ل خ ل ا ص ة ~}}$

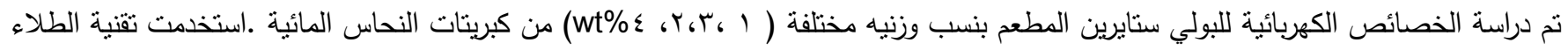

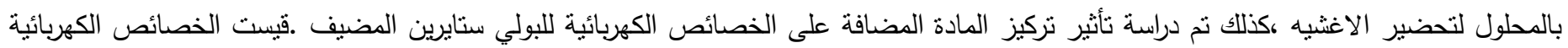

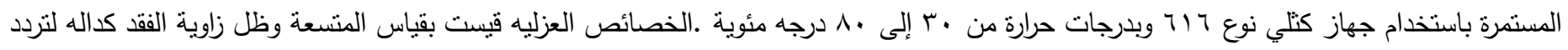

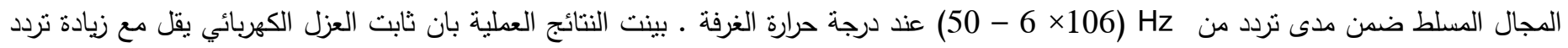

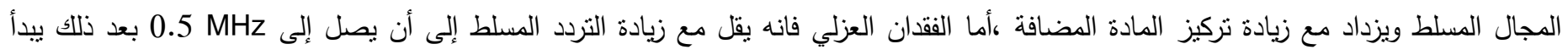

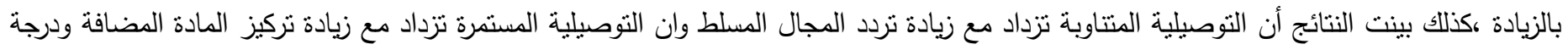
الحرارة وان طاقات التنشيط نقل مع زيادة تركيز الملح المضاف. 


\section{Introduction}

One of the distinct areas within polymer science is that of high temperature or thermally stable materials [1].In the recent years conjugated conducting polymers have been the mian focus of research throughout the world . Since the discovery led by 2000 chemistry Nobel winners, Shirakawa, MacDiarmid and Heeger , the perception that plastic could not conduct electricity has changed Nowadays, conducting polymers also known as conductive plastics are being developed for many uses such as corrosion inhibitors, compact capacitors, antistatic coating, electromagnetic shielding and smart windows; which capable to vary the amount of light to pass[ 2 ,3] . Electrical conduction in polymers have been extensively studied in recent years to understand the nature of charge transport in these material. Various conduction mechanisms such as Schottky effect, the pool-frenkel effect, space charge limited conduction and hopping conduction have been suggested for the charge transport[4]. Polystyrene is a preferred material in electronic technology due to its dielectric and mechanical properties and its low cost . PS can be subjected to high temperature and pressure variations, during the manufacture of electronic components [5].Electrical conductivity measurement is one of the most convenient tools in studying such structural changes of powder compacts, and has the advantage that the conductivity can de measured continuously throughout the whole densification process. The present work deals with the effect of $\mathrm{CuSO}_{4} .5 \mathrm{H}_{2} \mathrm{O}$ additive on dielectric and electrical properties of PS .

\section{Experimental}

\section{1-Materials}

Polystyrene doped with Copper sulfate was prepared with weight percent $(0,1,2,3$ and $\leqslant$ wt $\%)$ it was dissolved in glass beaker $(30 \mathrm{ml})$ by benzene using magnetic stirrer and placed in Petri dish ${ }^{\circ} \mathrm{cm}$ diameter using casting technique to prepare the films .Each sample was poured in $25 \mathrm{~cm}$ 'glass basin after being cleaned with water using ultrasonic device .The samples were put in dried oven at $50 \mathrm{C}^{\mathrm{O}}$ for $2 \mathrm{~h}$. The thickness of the dried samples are $(0.1$ to 0.15$) \mathrm{cm}$. The D.C conductivity measured by measuring the D.C electrical resistance using the( Keithly Electrometer type 616C), and for different temperatures ranging from $(30-80)^{\circ} \mathrm{C}$. The dielectric properties measured by measuring the capacitor and the loss angle tangent as a function to the alternating electric field frequency using the (Agilent impedance analyzer 4294A), within the frequency range $\left(50-6 \times 10^{6}\right) \mathrm{Hz}$ at room temperature. The experimental results showed that the dielectric constant is decrease with increase frequency of applied electrical field and increase with increasing concentrations, dielectric loss is increase with increasing frequency of applied electrical field to be $0.5 \mathrm{MHz}$ after this it was decreasing , A.C electrical conductivity are increasing with increasing frequency of applied electrical field ,also, the results showed that the D.C electrical conductivity are increasing with increase concentration of $\mathrm{CuSO}_{4}$ and temperature, activation energy are decreasing with increase concentration of additive salt .

\section{2-Theoretical}

The dielectric constant $(\varepsilon)$, is calculated by using the following expression:

$$
\varepsilon^{\prime}=\frac{\mathrm{Cd}}{\varepsilon_{\circ} \mathrm{A}}
$$

where $\mathrm{d}$ is the thickness of the films and A is surface area of the films

The dielectric loss $\varepsilon^{\prime \prime}$ is calculated by using the following equation

$$
\varepsilon^{\prime \prime}=\dot{\varepsilon} \times \tan \delta
$$

where $\tan \delta$ is dissipation factor.

The A.C conductivity ( $\sigma_{\mathrm{ac}}$ ) is calculated by the following equation:

$$
\sigma_{\mathrm{ac}}=\varepsilon_{\circ} \mathbf{W} \varepsilon^{\prime \prime}
$$

Where $\varepsilon o$ is the permittivity of free space and ( $w)$ is the angular frequency.

$$
\begin{aligned}
& \text { The volume electrical conductivity } \sigma_{v} \text { defined by : } \\
& \left.\qquad \sigma_{v}=\frac{1}{\rho_{v}}=\frac{L}{R A} \quad \ldots \ldots \ldots \ldots \ldots \ldots \text {........... } 4\right)
\end{aligned}
$$

Where :

$\mathrm{A}=$ guard electrode effective area.

$\mathrm{R}=$ volume resistance $(\mathrm{Ohm})$.

$\mathrm{L}=$ average thickness of sample $(\mathrm{cm})$.

In this model the electrodes have circular area $A=\pi D^{2} / 4$ where $\mathrm{D}=2.5 \mathrm{~cm}^{2}$. 
The activation energy was calculated by using the following equation:

$$
\sigma=\sigma_{0} \operatorname{EXP}\left(-E_{a c t} / K T\right)
$$

where $\sigma$ is electrical conductivity at T temperature, $\sigma_{\mathrm{O}}$ is electrical conductivity at absolute zero of temperature, $K_{B}$ is Boltzmann constant and $\mathrm{E}_{\mathrm{act}}$ is Activation Energy.

\section{3-Results and Discussion}

Figure (1) show electrical volume conductivity as function of the concentration of $\mathrm{CuSO}_{4} \cdot 5 \mathrm{H}_{2} \mathrm{O}$ at a temperature of $30^{\circ} \mathrm{C}$ from the figures we note the concentration increasing of $\mathrm{CuSO}_{4} .5 \mathrm{H}_{2} \mathrm{O}$ the conductivity increases, the increase of conductivity with increasing of concentration of $\mathrm{CuSO}_{4} \cdot 5 \mathrm{H}_{2} \mathrm{O}$ due to increases the charge carriers which increased with increasing filler contact where the $\mathrm{CuSO}_{4} .5 \mathrm{H}_{2} \mathrm{O}$ particles at a low concentrations are represented by small darker regions and become large when the $\mathrm{CuSO}_{4} .5 \mathrm{H}_{2} \mathrm{O}$ content increases but when the concentration of $\mathrm{CuSO}_{4} .5 \mathrm{H}_{2} \mathrm{O}$ reaches to $(2 \mathrm{wt} . \%)$, the network will be connected to each other containing the overlapping paths to allow the charge carriers to pass through, where the charge carriers with routes through which the electrical resistance be less[6, 7, 8].

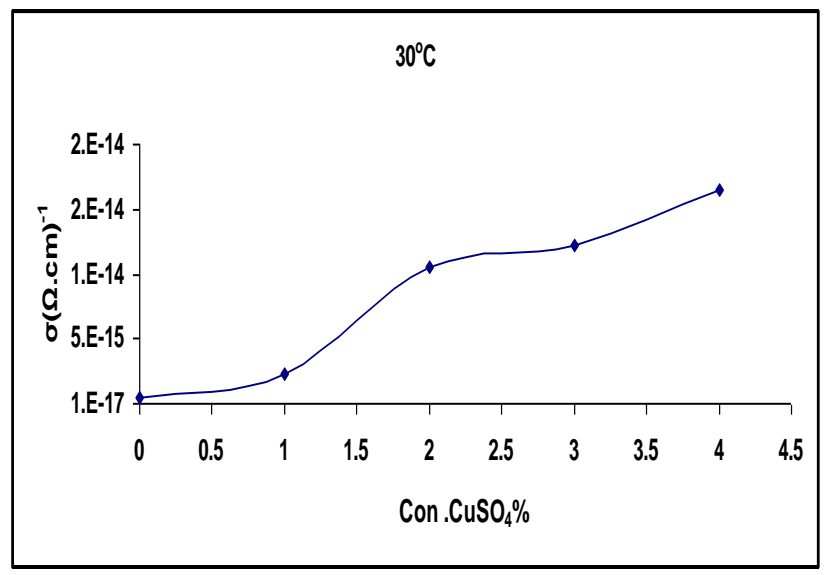

Figure (1)The electrical volume conductivity $\sigma$ $(\Omega . \mathrm{cm})^{-1}$ as a function of the wt $\%$ of Copper Sulfate at a temperature $30^{\circ} \mathrm{C}$

Figure (2) shows the behavior of electrical volume conductivity of the samples with the temperature. Note that the electrical conductivity increase with increasing temperature that any of this material has a negative thermal coefficient of resistance the interpretation of this is that the polymeric chains and $\mathrm{CuSO}_{4} \cdot 5 \mathrm{H}_{2} \mathrm{O}$ particles act as traps the charge carriers which transited by hopping process. on increasing the temperature , segments of the polymer being to move, releasing the trapped charges. The released of trapped charges is intimately associated with molecular motion. The increase of current with temperature is attributed to two main parameters, charge carriers and mobility of these charges. The increase of temperature will increase the number of charge carriers exponentially. The mobility depends on the structure and the temperature [3].

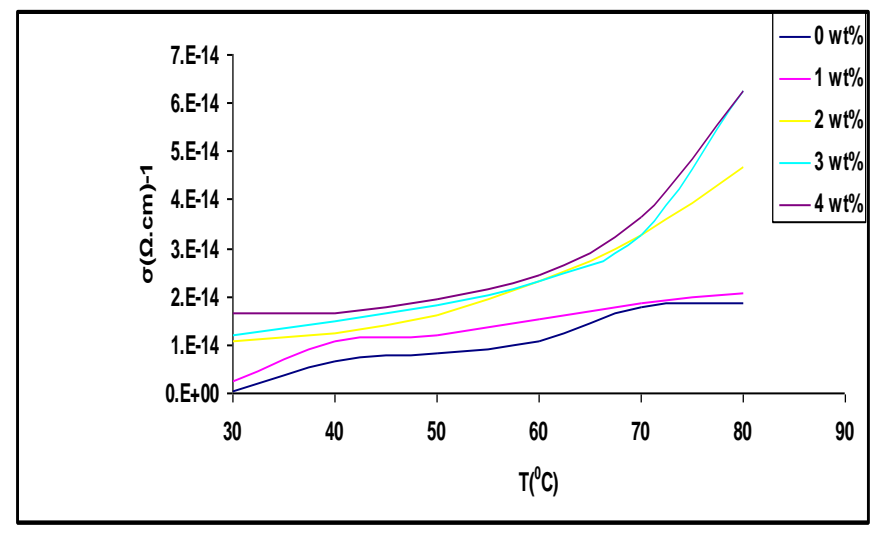

Figure $(r)$ : Electrical volume conductivity of the composite $\sigma_{\mathrm{v}}(\Omega . \mathrm{cm})^{-1}$ with the temperature

Figure (3) shows the relationship between the conductivity and inverted absolute temperature of the PS- $\mathrm{CuSO}_{4} .5 \mathrm{H}_{2} \mathrm{O}$ composites, using equation ( 6 ) was calculate activation energy and shows us to calculate the activation energy, high values to the activation energy ranges between $(0.35 \mathrm{eV}$ to $0.6 \mathrm{eV})$ for PS- $\mathrm{CuSO}_{4} .5 \mathrm{H}_{2} \mathrm{O}$ composites these values are due to the presence of free ions in the commercial polymers and the addition of low concentration of $\mathrm{CuSO}_{4} .5 \mathrm{H}_{2} \mathrm{O}$ reduced the activation energy values of all samples of PS- $\mathrm{CuSO}_{4} .5 \mathrm{H}_{2} \mathrm{O}$ composites the result of the space charge effect in the contact regions where the shipment in addition to the concentration of low-power levels localized in the forbidden energy gap act as traps to charge carriers and charge carriers were moving by Hopping as shown in figure (4) [9] . 


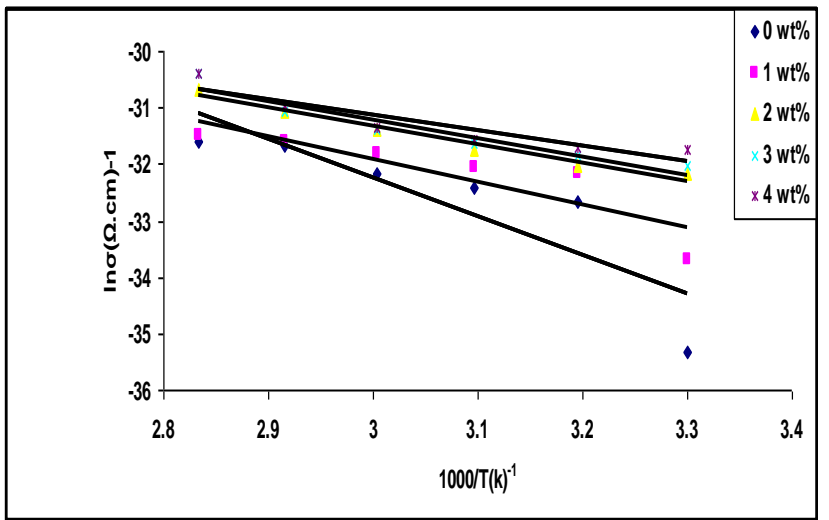

Figure (3) : Electrical volume conductivity of the composite $\sigma_{\mathrm{v}}(\Omega . \mathrm{cm})^{-1}$ with the temperature

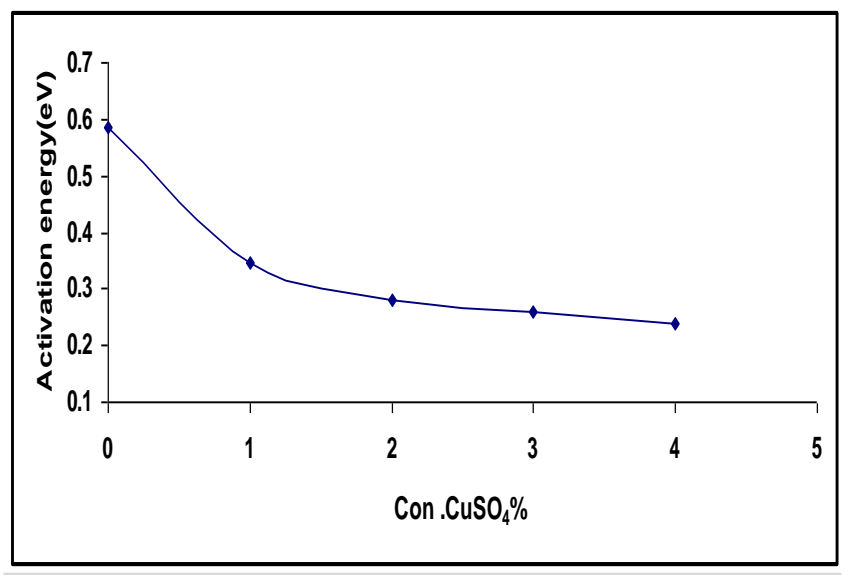

Figure (4): Activation energy and concentration of $\mathrm{CuSO}_{4} \mathrm{wt} \%$.

Figure (5) shows the variation of the dielectric constant of PS- $\mathrm{CuSO}_{4} .5 \mathrm{H}_{2} \mathrm{O}$ composites with angular frequency. The figure shows that the dielectric constant values decrease when increasing the applied field frequencies. The increase of frequencies results in decreasing of space charge polarization to the total polarization. The space charge polarization becomes the more contributing type of polarization at low frequencies, and less contributing with the increase of frequency; this would result in the decrease of dielectric constant values for all samples of PS- $\mathrm{CuSO}_{4} \cdot 5 \mathrm{H}_{2} \mathrm{O}$ composites with the increase of the electric field frequency $0.5 \mathrm{MHz}$.

The other types of polarizations appear at subsequent frequencies. The ionic polarization reacts slightly to the variation in the field frequencies compared to the electronic polarization. This is because the mass of ion is greater than that of the electron. The electrons respond to even the high frequencies of the field vibrations. The low mass of electron makes the electronic polarization the only type of polarization at higher frequencies. This makes the dielectric constant approximately constant for all samples at high frequencies $[10,11]$.

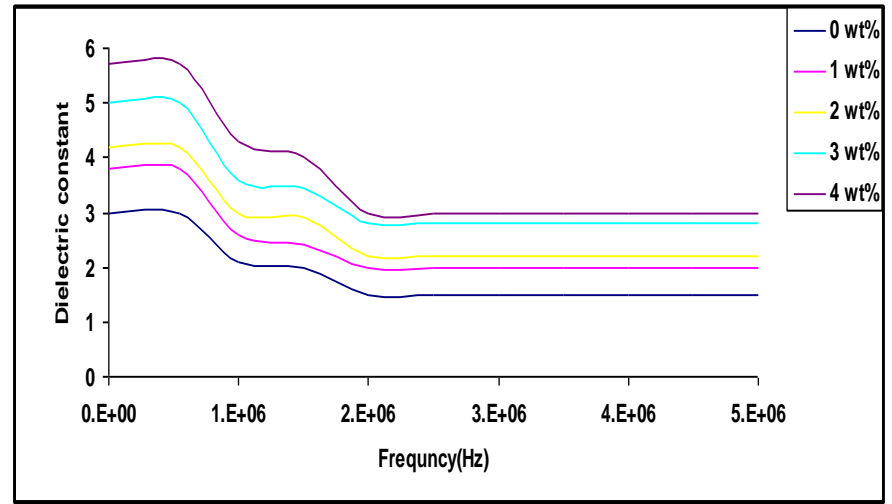

Figure (5): the variation of the dielectric constant of the composites with angular frequency.

Figure (6) shows the dielectric loss as a function of the angular frequency of $\mathrm{PS}-\mathrm{CuSO}_{4} \cdot 5 \mathrm{H}_{2} \mathrm{O}$ composites. When the applied field frequency is low, the dielectric loss value is low, and it is increasing when increasing the frequency. The dielectric loss increases till it reaches to the highest value at $(0.5 \mathrm{MHz})$. This value represents the highest dielectric loss at certain frequency, that is the highest absorption of applied field. This absorption happens due to Maxwell- Wagner phenomenon which is caused by A.C current due to the difference of dielectric constant and conductivity of the phases in the composite. This electric current has the same phase as that of the applied field $[12,13]$. When the frequency increase more than $0.5 \mathrm{MHz}$, the dielectric loss become constant. This is attributed to the mechanisms of other types of polarization that occurs at high frequencies. This is similar to the results reached by the researchers $[14,15]$. 


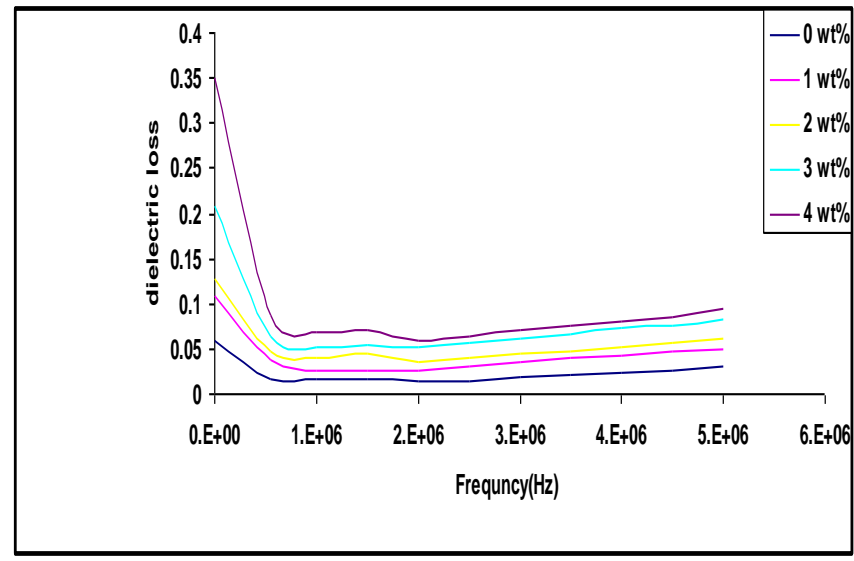

Figure (6) : Dielectric loss as a function of the angular frequency of the composites

Figure (7) shows the variation of the A.C conductivity for $\mathrm{PS}_{-} \mathrm{CuSO}_{4} .5 \mathrm{H}_{2} \mathrm{O}$ composites with angular frequency. The figures show that A.C conductivity increases considerably with the increase of frequency(f), this is attributed to the space charge polarization and also to the motion of charge carriers by hopping process. [16]. Consequently, the conductivity is increasing when increasing the frequency and weight percentage of the $\mathrm{CuSO}_{4} \cdot 5 \mathrm{H}_{2} \mathrm{O}$.

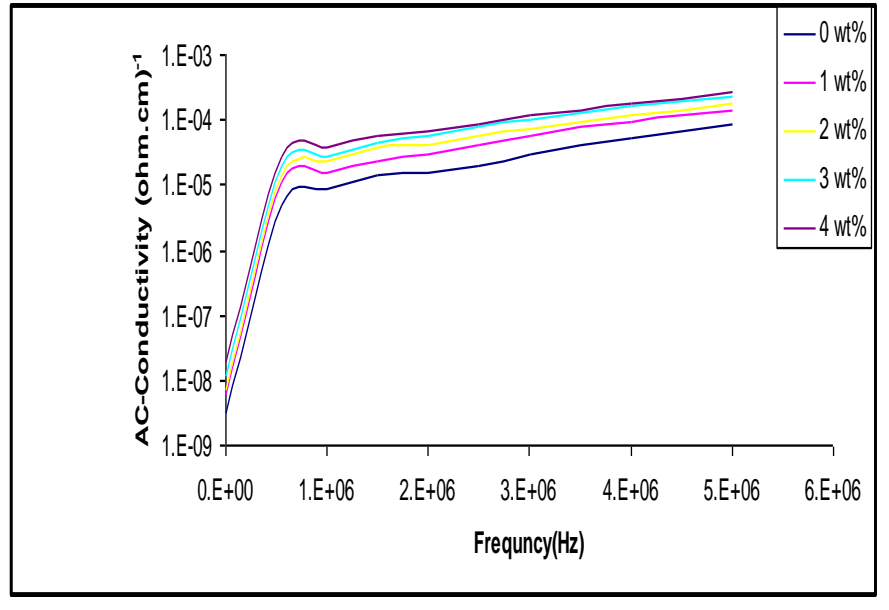

Figure (7) : AC conductivity for the composites with angular frequency

\section{Conclusions}

1-The dielectric constant, dielectric loss, ,A.C electrical conductivity and the D.C electrical conductivity increase with increasing $\mathrm{CuSO}_{4}$..
2-The dielectric constant is decreasing with the increase of frequency of the applied electric field .

3-The dielectric loss of low and high concentrations is oscillatory with the frequency of applied electric field . 4-The A.C electrical conductivity at all wt $\%$ is increase with increasing frequency of the applied electrical field 5-The activation energy for D.C electrical conductivity decreasing with increasing $\mathrm{CuSO}_{4}$.

\section{$\underline{\text { References }}$}

[1] Ataei, S, Akbarian L and Feizi R, 2007, "preparation, characterization, and properties of new generation of polyesters containing bulky groups",J. of polym., 16(9),p.(607-614).

[2] Harun .M., Saion E. and Kassim A, 2009,"Electrical properties of polyvinylalcohol -polypyrrole composites polymer films",J. for the advancement of science, Vol.1,No.1.

[3] Al-Ramadhan. Z. , 2008,"Effect of Nickel salt on electrical properties of polymethylmethacrylate" , $\mathrm{J}$. of college of education ,Al-Mustansiriyah Uni..No.3.

[4] Abdel-Malik. T. G. , Abdel- Latif R. and Ahmed S., 2008,"Electrical properties of pure and doped polyvinylAlcohol (PVA) films using Gold and Aluminum electrodes", El-minia Uni., Egypt.

[5] Tawansi , A.EL ,Xiao S. and Rong Z. , 1989,"Free volume coduction and magnetic solution in polystyrene composites containing transition metals", Egypt.

[7] He X. J., Du J. H. and Z. Ying, 2005, " positive temperature coefficient effect in multwalled carbon nanotube high - density polyethylene composite", Vol. 86 , J. Appl. Phys. Letters, China.

[6] Bhattacharya S., Sachdev V. K. and R. p. Tandon , 2008," Electrical Properties of Graphite filled polymer composites ", Delhi.

[8] Srivastava . N. K. and Mehra R. M., 2003," Study of electrical properties of polystyrene / foliated graphite composite " , Uni. Of Delhi South Campus. 
[9] Hamza M. h , E. Saion , A. Kassim and M. Yousuf , 2008, "Temperature dependence of AC Electrical conductivity of PVA-PPy- $\mathrm{FeCl} 3$ composites polymer Films", MPJ. Vol. 3, No. 2 , p(24-31), 2008 Malaysia .

[10] C. Chiteme , S. Lowther and S. Harrison , J. of Polym.Science, Vol. 43, PP(3273-3287), 2005.

[11] M. Hamzah , E. Saion , A. Kassim , E. Mahmud and I. Shahrim, J. for the advancement of sci. Vol. 1, No. 1, P(9-14), 2009.

[12] B. H AL-Khayat and F. A. Awni J. Am. Ceram. Soc. Bull. 64(4), pp(598-601), 1985.

[13] M.Revanasiddappa, S.C. Raghavendra, S. Khasim and T. KVishnuvardhan , J.Bull. Korean chem.. Soc. Vol. 28 , No.7PP(1104-1108), 2007

[14] P. K. Pillal , P. Khurana and A. Tripathi , J. of materials Sci. letters, Vol. 5, pp(629-632), 1986.

[15] S. Satapathy , P. K. Gupta , K. B. R. Varma , P. Tiwari andV. Ganeshan, "study on dielectric behavior of Lithium Tantalate (LT) nano particl filled poly(vinylidene fluoride) (PVDF) nano composites", Institute of Science, Srinu73@cat.ernet.in, India, 2008.

[16] T. K. Vishnuvardhan ,V. R. Kulkarni,C. Basavaraja and S.C. Raghavendra, J.Bull. Mater. Sci. Vol. 29 , No. 1, pp. 77-83, 2006. 